\begin{abstract}
In a classic study (Izard, 1971), children were shown an array of facial expressions and asked to choose the person who expressed a specific emotion. Children were later asked to name the emotion in the face with any label they wanted. Subsequent research often relied on the same two tasks -- choice from array and free labeling - to support the conclusion that children recognize basic emotions from facial expressions. Here, five studies ( $\mathrm{N}=120 ; 2-10$-year-olds) showed that these two tasks produce illusory recognition: a novel nonsense facial expression was included in the array. Children 'recognized' a nonsense emotion (pax or tolen) and two familiar emotions (fear and jealousy) from the same nonsense face. Children likely used a process of elimination: they paired the unknown facial expression with a label given in the choice-fromarray task, and, after just two trials, freely labeled the new facial expression with the new label.

$\underline{\text { These data indicate that past studies using this method may have overestimated children's }}$ expression knowledge.
\end{abstract}

Keywords: facial expressions; emotion; jealousy; fear; children; process of elimination

(C) 2015. This manuscript version is made available under the Elsevier user license http://www.elsevier.com/open-access/userlicense/1.0/ 


\section{A Facial Expression of Pax: Assessing Children's “Recognition” of Emotion from Faces}

When presented with an array of facial expressions (such as those claimed to signal happiness, sadness, and fear) and asked to find the person who is afraid, children as young as two years of age select the predicted expression more often than would be expected by chance. The assumption has been that the task reveals children's prior knowledge of what emotion is signaled by, in this case, the fear expression. Here we present evidence that at least some of this knowledge can be, instead, created by the experiment.

Evidence from the choice-from-array task has been claimed to show that young children recognize happiness, sadness, anger, fear, surprise, disgust, and even pride (Denham, McKinley, Couchoud \& Holt, 1990; Gagnon, Gosselin, Hudon-ven der Buhs, Larocque \& Milliard, 2010;

Gagnon, Gosselin, \& Maassarani, 2014; Harrigan, 1984; Izard, 1971; Kayyal \& Russell, 2013;

McClure, 2000; Nelson \& Russell, 2015a; Székely et al., 2011; Tracy, Robins \& Lagattuta,

2005). Izard (1971) showed that, following the choice-from-array task, children also freely label the facial expression with the predicted emotion label. Indeed, children as young as two years of age produce the expected label for at least some of the same expressions (Gates, 1923; Izard, 1971; Markham \& Adams, 1992; Nelson \& Russell, 2011a; Widen, 2013; Widen \& Russell, 2003; 2008), again complementing the conclusion that young children recognize emotions from facial expressions. Many subsequent studies of children used the same tasks: choice-from-array and free labeling.

The idea of recognition of certain facial expressions in early childhood is embedded within the prevailing conceptual framework in the science of emotion, namely, basic emotion theory. Evidence with young children complements evidence from remote cultures (Ekman, 1980) and from people born with congenital blindness (Tracy \& Matsumoto, 2008). Although 
basic emotion theory does not predict the precise age at which children can recognize basic emotions from their facial expressions, some researchers have offered evidence that such recognition occurs in the first year of life, (Hoehl \& Striano, 2010; Martens, Hamlin, \& Tracy, 2013; Izard, 2011; Izard, Woodburn \& Finlon, 2010). Such evidence resonates with basic emotion theory because early recognition fits with its evolutionary account in which caregivers can signal to a pre-verbal child that, for example, a certain animal is dangerous or a certain food is disgusting; the child who then avoids the present harm is more likely to survive (Izard, 1994).

In this article, we argue that the choice-from-array task can yield illusory recognition: children can "recognize" various, even non-existent, emotions from the same made-up nonsense expression - an expression that no one has proposed as a signal of any emotion. When children know some face-label pairings, they can then use a process of elimination to match the unknown face to a label not yet paired with a face. A fast-mapping process may then allow the child to learn, with just one or two exposures, the new label associated with the new expression. When the choice-from-array task is followed by a free labeling task (as in Izard, 1971, for example), the child then uses their newfound knowledge of the face and label pairing to label the expression with the expected label. If children used this strategy in emotion recognition tasks in prior research, they would have appeared to recognize the correct emotion from an expression in both the choice-from-array and subsequent free labeling tasks -- even if they were unfamiliar with either the emotion label or expression presented.

Preschoolers and toddlers have been shown to use the process of elimination as a word learning strategy; children match unfamiliar labels to objects or properties that they do not yet have a label for including color (Carey \& Bartlett, 1978), objects (Au \& Markman, 1987), animals (Au \& Glasman, 1990), verbally provided facts (Waxman \& Booth, 2000), adjectives 
(Diesendruck, Hall \& Graham, 2006), and actions (Waxman, Lidz, Braun \& Lavin, 2009). It is not known, however, if process of elimination and fast mapping occur with facial expressions. Of course, if children already know which basic emotionemetions goes with awhich facial expression, an elimination strategy would not be necessary. Whether children use a process of elimination when confronted with an array of facial expressions has not, to our knowledge, been explored.

\section{Overview}

To determine whether children can use a process of elimination in choice-from-array tasks to match novel labels to novel expressions, as well as known labels to novel expressions, we conducted five studies in which children (two- to four-year-olds and five- to ten-year-olds) were presented arrays of facial expressions. In each array, the facial expressions, such as those for happiness and sadness, were likely familiar to children (Bullock \& Russell, 1985; Camras \& Allison, 1985; Denham \& Couchoud, 1990; Nelson, Hudspeth, \& Russell, 2013; Nelson \& Russell, 2011b; Widen \& Russell, 2003) - with one exception. One expression in each array was novel (puffed cheeks), , and children were unlikely to be familiar with it. Children were then asked to find in the array a face that expressed a certain emotion. Some of the emotion labels were familiar and applied to an expression in the array (e.g.(e.g. "Do you see anyone who feels happy?"). Other?"'), and alse labels, however, that did not apply to an expression in the array, either because the hypothesized expression was not present (e.g. "Do you see anyone who feels afraid?"), or because the labels were nonsensical (e.g.the expressions in the array (e.g. "Do you see anyone who feels pax?"). If children do not use a process of elimination, they can simply state "No one feels pax." If children use a process of elimination to determine which face to choose for a given label, then they are likely to match the novel face with the novel non-word 
pax. If so, a consensus would emerge on an illusory recognition: the novel face as an expression of pax.

The first three studies asked whether children use a process of elimination to match a novel label to a novel expression: Study 1A concerned 2-4 year olds; Studies 1B and 1C concerned 5-10 year olds; Study 1C examined more carefully the alternative explanation that children simply did not realize that they could say that none of the faces match the emotion

asked for. The last two studies examined moreasked whether children use this process even with familiar labels rather than the nonsense labels of the first three studies: Study 2A concerned fear; and Study 2B jealousy. Across these five studies, we examined whether children would use a process of elimination to match a label to a novel expression.

\section{Study 1A}

Preschoolers viewed arrays of three facial expressions - happiness, sadness, and a novel expression - and were presented with the labels happy, sad, and pax (or tolen, in half of the cases). The dependent measure was whether children would match the novel label with the novel expression and therefore appear to 'recognize' the novel expression even though they were unfamiliar with it or the label. As a final trial, children freely labeled each expression to determine whether the associations made during the choice-from-array task between the novel expression and label would be applied in a subsequent task. Study 1A was not designed to show that children know nothing of the emotion conveyed by facial expressions - indeed, the method presupposes that the children are familiar with the facial expressions for happy and sad. Rather - rather, the study was designed to show that the choice-from-array task can yield the appearance of knowledge where none exists.

\section{Method}


Participants. Participants were 24 children, with eight 8 children in each of three age groups: two-year-olds ( $\mathrm{M}=29.5$ mos., $\mathrm{SD}=3.2$ mos. $)$, three-year-olds $(\mathrm{M}=41.6$ mos., $\mathrm{SD}=2.7$ mos.), and four-year-olds $(\mathrm{M}=55.5$ mos., $\mathrm{SD}=1.9$ mos. $)$. Each age group included an equal number of males and females. In addition, two adult comparison groups ( $\mathrm{N}=10$ per group) evaluated the materials for this series of studies.

Materials. One female and one male adult each posed expressions of happiness, sadness, anger, and an expression not previously associated with any emotion: a puffed-cheeks expression (Action Unit $=34 ;$ Ekman \& Friesen, 1978). An example of the novel expression is shown in Figure 1. One adult comparison group $(\mathrm{N}=10)$ rated the puffed-cheeks expression plus several other novel expressions as positive or negative in valence, answering the question "Is this person feeling positive or negative?". Half of the adults rated the puffed-cheeks expression as positive and half rated it as negative; therefore, this expression was chosen as a novel expression that was ambiguous in valence. The second adult comparison group $(\mathrm{N}=10)$ freely labeled the emotion conveyed by the puffed-cheeks expression. In response to the question "How does she/he feel?" 3 participants labeled the expression as frustrated, and 2 labeled it as overwhelmed. All other labels (angry, bloated, full, nauseous, sick) were generated only once. The varied responses generated for the expression indicated that it was not viewed as conveying any single, specific emotion.

Procedure. Before participating, children were randomly assigned to hear one of two novel labels: pax or tolen. 
Animal labeling. As a familiarization task, and to ensure that children realized that on some trials the correct answer is that none of the photos contain what was asked for, children were first presented an array of three animal pictures: a cat, a dog, and a rabbit. The experimenter asked: "Do you see a cat (dog, rabbit)?" Children were asked to identify each animal in the array once. To make explicit that, on some occasions, "no" was the correct answer in this task, children were also asked "Do you see an elephant?" (not present in the array) during the questioning. If the child indicated that one of the animals was an elephant, the experimenter said: "No, that's not an elephant, is it?" and repeated the question until the child acknowledged that there was no elephant in the array. All children acknowledged the absence of an elephant in the array and were praised for 'not getting tricked' by the experimenter. All children also correctly chose all animals in the array as requested by the experimenter.

Priming. Children next underwent a priming procedure to increase the accessibility of the emotion labels as well as to introduce the novel label. The experimenter initiated a conversation with the child about feelings and asked questions such as "happy is a feeling; have you ever felt happy?" Children's responses to the experimenter's question were not corrected. The labels targeted in the priming session were those that were to be presented in the studyhappy, sad and pax (or tolen, in half of cases).

Choice-from-array task. For the first array, children viewed three facial expressions, which were arranged in random order and remained on the table throughout the trial (happiness, sadness, and puffed-cheeks). The expressions were posed by either a male or a female poser and the order of presentation was counterbalanced. The experimenter asked for emotions in a predetermined order. Children were first asked: "Do you see anyone who feels happy?" This question was phrased in such a way that children would not assume that a person displaying the 
given emotion was in the array, and could answer the experimenter with "no". After the child pointed to an expression (or responded that no one felt happy), children were then asked if they saw anyone who felt sad, and finally, pax.

For the second array, children viewed expressions of happiness, sadness, and puffedcheeks, posed by a different poser (either male or female, counterbalanced). The order of label presentation was partially random; first, children were either asked if they saw anyone who felt happy or anyone who felt sad. Second, children were asked if they saw anyone who felt pax. Pax was presented second so that if children were using a process of elimination to match labels to expressions, they would still have to choose between the two remaining expressions that they had not yet selected. Third, children were asked to find the emotion not asked for on the first trial (e.g.: if happy was asked for on the first trial, sad would be asked for on the third trial).

Free Labeling Task. Next, children freely labeled the happy, sad, and puffed-cheeks expressions they saw in the first choice-from-array trial. Children were shown each picture one at a time, in a random order, and were asked, "How does he/she feel?" Children were free to give any emotion label they chose.

Scoring. For the choice-from-array task, children's responses were coded for whether they matched the expected label with the expected expression or not (coded as a 1 or 0 ). For each emotion category, children's scores across the two arrays were averaged, resulting in a recognition score ranging between 0 and 1 . For the free labeling task, children's responses were sorted by three independent coders into one of the following categories: happiness, sadness, anger, fear, surprise, disgust, or pride. Any responses for which coders could not agree were categorized as other. Responses categorized as correct for happiness were: happy; for sadness were: sad; for pax were: pax, paxes; for tolen were: tolen. 


\section{Results}

As shown in Table 1, the mean recognition score for preschoolers' matching of the novel label with the novel expression was $67 \%$. This percentage is significantly greater than the $33 \%$ that would be expected by chance guessing (if children did assume that one of the three expressions was the pax face, their likelihood of choosing any expression would be one in three for each array, averaged across the two trials $=33 \%$ ), as determined by a single sample t-test,

Table 1. Percentage of children, by age, in each study matching the novel label with the novel expression.

\begin{tabular}{|c|c|c|c|c|}
\hline & \multicolumn{3}{|c|}{ Matching Novel Expressions to Novel Labels } & \multirow[b]{2}{*}{ Mean } \\
\hline & Study $1 \mathrm{~A}$ & Study $1 \mathrm{~B}$ & Study $1 \mathrm{C}$ & \\
\hline \multicolumn{5}{|c|}{ Choice-From-Array Task } \\
\hline 2-year-olds & 38 & -- & -- & 38 \\
\hline 3 -year-olds & 81 & - & -- & 81 \\
\hline 4-year-olds & 81 & -- & -- & 81 \\
\hline 5- and 6-year-olds & -- & 63 & 81 & 72 \\
\hline 7- and 8-year-olds & -- & 88 & 75 & 82 \\
\hline 9- and 10 -year-olds & -- & 63 & 88 & 76 \\
\hline Mean & 67 & 71 & 81 & 73 \\
\hline \multicolumn{5}{|c|}{ Free Labeling Task } \\
\hline 2-year-olds & 13 & -- & -- & 13 \\
\hline 3-year-olds & 38 & - & -- & 38 \\
\hline 4-year-olds & 75 & -- & -- & 75 \\
\hline 5- and 6-year-olds & -- & 50 & 38 & 44 \\
\hline 7-and 8-year-olds & -- & 88 & 63 & 76 \\
\hline 9- and 10 -year-olds & -- & 50 & 100 & 75 \\
\hline Mean & 42 & 63 & 67 & 57 \\
\hline
\end{tabular}

Note. The target label was either pax or tolen.

$t(23)=4.33, p<.001$. Each child had two opportunities to respond that no one in the array felt pax. For only five of these 48 trials did children respond by saying 'no' or refuse to provide an 
label (either pax or tolen), as shown in Table 1. This finding indicates that children were

respending in a nen randem manner, as the likelihøed of children spentaneeusly labeling the novel expression as pax (without prior exposure to the expression and label in the choice fromarray task) is effectively zero.

Table 1. Percentage of children, by age, in each study matching the novel label with the novel expression.

\begin{tabular}{|c|c|c|c|c|}
\hline & \multicolumn{3}{|c|}{ Matching Novel Expressions to Novel Labels } & \multirow[b]{2}{*}{ Mean } \\
\hline & Study $1 \mathrm{~A}$ & Study $1 B$ & Study $1 \mathrm{C}$ & \\
\hline \multicolumn{5}{|c|}{ Choice-From-Array Task } \\
\hline 2-year-olds & 38 & -- & -- & 38 \\
\hline 3 -year-olds & 81 & -- & -- & 81 \\
\hline 4-year-olds & 81 & -- & -- & 81 \\
\hline 5- and 6-year-olds & -- & 63 & 81 & 72 \\
\hline 7- and 8-year-olds & -- & 88 & 75 & 82 \\
\hline 9- and 10 -year-olds & -- & 63 & 88 & 76 \\
\hline Mean & 67 & 71 & 81 & 73 \\
\hline \multicolumn{5}{|c|}{ Free Labeling Task } \\
\hline 2-year-olds & 13 & -- & -- & 13 \\
\hline 3-year-olds & 38 & -- & -- & 38 \\
\hline 4-year-olds & 75 & -- & -- & 75 \\
\hline 5- and 6-year-olds & -- & 50 & 38 & 44 \\
\hline 7- and 8-year-olds & -- & 88 & 63 & 76 \\
\hline 9- and 10 -year-olds & -- & 50 & 100 & 75 \\
\hline Mean & 42 & 63 & 67 & 57 \\
\hline
\end{tabular}

Note. The target label was either pax or tolen.

Not surprisingly, children scored higher with happy and sad faces than with the novel face. To determine whether children's performance matching the novel label with the novel expression in the choice-from-array task differed significantly from their matching of the labels happy and sad with the expected expressions, we performed a 3 (age group) x 3 (emotion label) mixed-design repeated measures ANOVA using children's recognition scores as the dependent variable. Children's performance increased with age, $F(2,21)=5.11, p=.02, \eta_{\mathrm{p}}{ }^{2}=.33$. Fouryear-olds' performance was greater than that of two-year-olds $(p=.02)$, and three-year-olds ( $p=$
Formatted: Don't add space between paragraphs of the same style 
.009). Single sample t-tests indicated that two-year-olds' performance was not greater than the $33 \%$ that would be expected by chance guessing, $t(7)=.36, p>.72$, whereas performance of three-year-olds, $t(7)=5.27, p=.001$, and four-year-olds, $t(7)=3.66, p=.007$, was greater than chance. In addition, a main effect of emotion emerged; Least Significant Difference (LSD) posthoc tests showed that children were more likely to match the expected label with the expressions of happiness and sadness than with the novel expression $F(2,42)=6.41, p=.003, \eta_{\mathrm{p}}^{2}=.23$ (all $p \mathrm{~s}<.04)$ (Table 2).

For the free labeling task, $42 \%$ of children labeled the novel expression with the novel label (either pax or tolen), as shown in Table 1. This finding indicates that children were responding in a non-random manner, as the likelihood of children spontaneously labeling the

Table 2. Percentage of children in each study who matched the expected label and expression, by emotion.

\begin{tabular}{|c|c|c|c|c|}
\hline \multicolumn{5}{|c|}{ Matching Novel Expressions to Novel Labels } \\
\hline \multirow{2}{*}{$\begin{array}{r}\text { Table 2. Percentage of ch } \\
\text { Happy }\end{array}$} & $\begin{array}{l}\text { Study } 1 \mathrm{~A} \\
\text { en in each stur }\end{array}$ & $\begin{array}{l}\text { Study 1B } \\
\text { ty who matched the expecte } \\
\text { Choice-From-Array Task }\end{array}$ & $\begin{array}{l}\text { Study 1C } \\
\text { t label and e }\end{array}$ & $\begin{array}{l}\text { Mean } \\
\text { tion. }\end{array}$ \\
\hline & 92 & 98 & 92 & 94 \\
\hline \multirow{2}{*}{$\begin{array}{r}\text { Sad } \\
\text { Novel }\end{array}$} & \multicolumn{3}{|c|}{ SAatching Novel Expgejssions to Novel Laggels } & 88 \\
\hline & Study $1 \mathrm{~A}$ & Study 1B & Stugy 1C & Mȩan \\
\hline \multirow{2}{*}{$\begin{array}{c}\text { Angry } \\
\text { Happd }\end{array}$} & -- & Choice-Froph-Array Task & 96 & 85 \\
\hline & 92 & 998 & $96^{2}$ & $95^{4}$ \\
\hline & 80 & 850 & $91^{2}$ & 858 \\
\hline $\begin{array}{l}\text { Mean } \\
\text { Novel }\end{array}$ & 67 & Free Labeting Task & 81 & 73 \\
\hline $\begin{array}{l}\text { Angry } \\
\text { Happy }\end{array}$ & $7 \overline{1}$ & $96^{73}$ & 188 & 895 \\
\hline Surprised & $7 T$ & 96 & 926 & 865 \\
\hline $\begin{array}{l}\text { Mean } \\
\text { Novel }\end{array}$ & 82 & 63 & 67 & 595 \\
\hline \multirow{2}{*}{$\begin{array}{c}\text { Angry } \\
\text { Happd }\end{array}$} & -- & Free Labeling Task & 67 & 75 \\
\hline & 71 & 926 & $88^{0}$ & 98 \\
\hline $\begin{array}{r}\text { Mean } \\
\text { Sade. The target labetgua } \\
\text { Not }\end{array}$ & 61 & 86 & 83 & 86 \\
\hline \multicolumn{2}{|c|}{ Note. The target labelaves either $p a x^{4}$ br tolen } & 63 & 67 & 57 \\
\hline Angry & -- & 83 & 67 & 75 \\
\hline Surprised & -- & 92 & 88 & 90 \\
\hline Mean & 61 & 86 & 83 & 77 \\
\hline
\end{tabular}

Note. The target label was either pax or tolen. 
AFor the free labeling task, a 3 (age group) x 3 (expression) mixed-design repeated measures ANOVA showed that children's labeling of the expressions increased with age, $F(2$, 21) $=5.92, p=.009, \eta_{\mathrm{p}}{ }^{2}=.36$. Children were also more likely to label the happy and sad expressions with the expected label than the novel expression $F(2,42)=4.97, p=.02, \eta_{\mathrm{p}}{ }^{2}=.19$ (all p’s <.009).

\section{Discussion}

In the choice-from-array task, children selected the happy expression when asked to find the happy person and selected the sad expression when asked to find the sad person. And $67 \%$ of children 'recognized' the novel expression as pax or tolen. These data are the first to show that children as young as three years of age match a novel label with a novel expression in the choice-from-array task even when they have no prior knowledge of the expression or label presented.

Prior to participating in this study, the children were unfamiliar with the novel label and novel expression. Yet, after only two exposures to the novel expression, each posed by a different actor, nearly half of the children (including $75 \%$ of four-year-olds) freely labeled it with the novel label. Children appeared to 'recognize' the emotion presented, and they presumably formed the association between the label and the expression during the choice-from-array task. Had we believed that the puffed checks signaled a basic emotion, the method in this study would have yielded evidence that preschoolers 'recognize' that signal.

\section{Study 1B}

It might be argued that two- to four-year-olds use a process of elimination to match labels and expressions because of their youth or their relative inexperience in observing others' facial expressions. Perhaps, the performance of these younger children does not necessarily reflect the 
manner in which older children match emotion labels to expressions, and older children may be more likely to identify the novel expression as unfamiliar or non-emotional. To determine whether older children would match a novel label to a novel emotional expression, we replicated Study $1 \mathrm{~A}$ with five- to ten-year-old children. To ensure that the tasks were not overly easy, we included five expressions in the array shown each child.

\section{Method}

The method was identical to that of Study 1A with the following exceptions.

Participants. The ages of participants were: five and six-year-olds $(\mathrm{M}=70$ mos., $\mathrm{SD}=$ 5.6 mos.), seven and eight-year-olds ( $\mathrm{M}=88$ mos., $\mathrm{SD}=4.8$ mos.), and nine and ten-year-olds $(\mathrm{M}=122$ mos., $\mathrm{SD}=7.8$ mos. $)$. No adult groups were used.

Procedure. Children were primed using the five labels to be presented in the study happy, sad, angry, surprised, and pax (or tolen, in half of cases).

Choice-from-array task. Each of the two arrays included five facial expressions, three of which were the same as those used in Study 1A (happiness, sadness, and puffed-cheeks). In addition, expressions of surprise and anger were included, posed by the same male and female posers from Study 1A.

Free Labeling Task. Children freely labeled all five expressions they saw in the first choice-from-array trial.

Scoring. For the free labeling task, responses scored as correct, in addition to those categorized in Study 1A, were: for anger: angry, frustrated, and mad; for surprise: surprised.

\section{Results}


As shown in Table 1, the mean recognition score for children's matching of the novel label and the novel expression was $71 \%{ }^{1}$. This percentage is significantly greater than the $20 \%$ that would be expected by chance guessing, $t(23)=6.00, p<.001$. Each child had two opportunities to respond that no one in the array felt pax. For only three of these 48 trials did children respond in such a way; in all other trials, an expression was selected for the pax label.

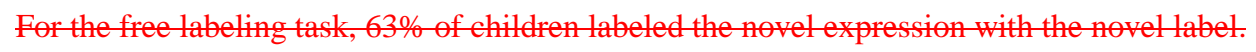

For the choice-from-array task, a 3 (age group) x 5 (emotion label) mixed-design repeated measures ANOVA found that children's performance varied with emotion, $F(4,84)=$ $6.22, p<.001, \eta_{\mathrm{p}}^{2}=.23$ (Table 2). Children were most likely to match the expected label with the expressions of happiness, sadness, and surprise, followed by anger and the novel expression (all $p s<.02)$.

\footnotetext{
${ }^{1}$ When asked to provide a definition of the word pax or tolen, a majority (58\%) of children referenced an emotion, suggesting that children did believe the label was emotional. See Supplemental Information for procedural information and data.

Formatted: Don't add space between paragraphs of the same style $\underline{\text { label. Aa }} 3$ (age group) x 5 (expression) mixed-design repeated measures ANOVA showed that children were more likely to label the happy, sad, angry and surprised expressions than the novel expression, $F(4,84)=4.82, p=.002, \eta_{\mathrm{p}}{ }^{2}=.19($ all $p$ 's $<.02)$.

\section{Discussion}

This study replicated with older children results found with preschoolers in Study 1A: $71 \%$ of children 'recognized' the novel expression as pax or tolen, and $63 \%$ freely labeled the novel expression as pax or tolen. Five- to ten-year-olds appeared to 'recognize' the emotion presented. The results of Study 1A were not simply an artifact of preschoolers' relative 
inexperience. Five- to ten-year-olds typically show near adult-like recognition scores (Izard, 1971), and yet the majority of children did not state that no one in the array felt pax or tolen, nor did many of them state that the labels pax or tolen were unfamiliar when asked for a definition. The apparent recognition of at least some emotions seen in prior studies by even ten-year-olds may be illusory. Over just two trials, they acquire new emotional labels and use a process of elimination to match them to a novel facial expression.

\section{Study 1C}

It might be argued that the five- to ten-year-old children of Study 1B matched a novel label to a made-up expression only because they felt reluctant to say that no one in the array felt pax -- despite the animal priming session in which they were praised for correctly stating that there was no elephant in the array. Children may have seen the animal and expression tasks as separate or may have simply been unwilling to answer no when presented with facial expressions. Therefore, we replicated Study 1B, omitting the happy expression from the array, but still asking children if anyone in the array felt happy. Because even young children consistently freely label the happy expression with the expected label (Widen \& Russell, 2008), if older children say no when asked if anyone feels happy, then a failure to say no when asked if anyone feels pax would suggest that our results accurately reflect children's use of a process of elimination. On the other hand, if five- to ten-year-old children are unwilling to say that no one in the array is happy, then it is possible that our results are due to the demands of the choicefrom-array task.

\section{Method}

The method was identical to that of Study 1B with the following exceptions. 
Participants. The ages of participants were: five and six-year-olds ( $\mathrm{M}=67$ mos., $\mathrm{SD}=$ 3.5 mos.), seven and eight-year-olds ( $\mathrm{M}=99$ mos., $\mathrm{SD}=6.2 \mathrm{mos}$.), and nine and ten-year-olds ( $\mathrm{M}=117$ mos., $\mathrm{SD}=4.9$ mos. $)$.

Procedure.

Choice-from-array task. Each array included four facial expressions (sadness, anger, surprise, and puffed-cheeks). For the first array, the experimenter asked for emotions in the following predetermined order: happy, sad, angry, surprised, pax. For the second array, the order of label presentation was partially random; children were asked if they saw anyone who felt pax on the third trial; all other emotions were ordered randomly.

Free labeling task. Children freely labeled the four expressions they saw in the first choice-from-array trial, plus the happy expression posed by the poser in the other expressions.

\section{Results}

First, were children willing to say no? Each child had two opportunities to respond that no one in the array felt happy, and for all but four of these 48 trials, children did so. Similarly, each child had two opportunities to respond that no one in the array felt pax. For only four of these 48 trials did children respond in such a way; in all other trials, an expression was selected for the pax label. As shown in Table 1, children's matching of the novel label and the novel expression was $81 \%$. This percentage is significantly greater than the $20 \%$ that would be expected by chance guessing, $t(23)=9.27, p<.001$. 
For the free labeling task, $67 \%$ of children labeled the novel expression with the novel label. As all children labeled the happy expression as happy; we therefore did not include it in the ANOVA. A 3 (age group) x 4 (expression) mixed-design repeated measures ANOVA showed an age effect, such that nine- and ten-year-olds were more likely to label expressions with the expected term than five- and six- and seven- and eight-year-olds, $F(2,21)=4.12, p=$ $.03, \eta_{\mathrm{p}}{ }^{2}=.28$. In addition, the effect of emotion showed that children were more likely to label the sad expression than the angry or novel expressions, $F(3,63)=3.06, p=.03, \eta_{\mathrm{p}}{ }^{2}=.13$ (all $p$ 's $<.02)$.

\section{Discussion}

Children were willing to answer no when asked whether anyone in the array was happy, and yet few answered no when asked whether anyone was pax. When asked if anyone felt pax, $81 \%$ of children 'recognized' the novel expression as pax, and $67 \%$ freely labeled it as pax. Our results in Study 1B were not simply due to experimenter demands of the choice-from-array task or to children's unwillingness to say no when presented an array of expressions.

\section{Study 2A}

It is possible that children matched the novel expression in the previous studies with novel labels because they believed they were simply learning a synonym for emotion concepts they were already familiar with, or because they had no preexisting ideas about the meaning of the words pax or tolen. However, when If so, then children know the meaning of an emotion label (fear, for example), they may then refusebe unwilling to match that label with an unfamiliar, novel expression. To determine whether our previous findings were simply due to

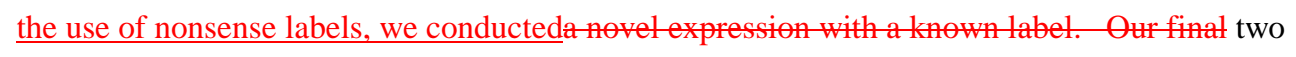

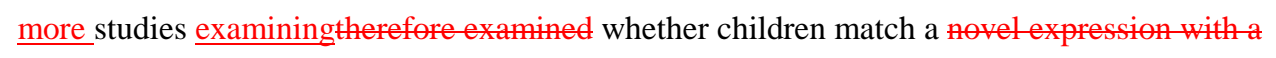

Formatted: Don't add space between paragraphs of the same style

Formatted: Highlight 
known emotion label with a novel expression. Study 2A used a known label considered a basic emotion (fear), and Study 2B used a known label that is not considered a basic emotion (jealous).

The emotion of fear is among the most common emotion labels used by preschoolers, as illustrated in the CHILDES database (Wellman, Harris, Banerjee \& Sinclair, 1995). In addition, as discussed earlier, prior research has shown that preschoolers associate the emotion of fear with expressions intended to convey fear (Izard, 1971; Markham \& Adams, 1992; Wiggers \& van Lieshout, 1985), as well as with stories depicting fearful situations (Camras \& Allison, 1985; Widen \& Russell, 2002; Wiggers \& van Lieshout, 1985). Taken together, these studies suggest that preschoolers are familiar with many aspects of the concept of fear including the associated label, expression, and situations. Therefore, we replicated Study 1A but,rather than presenting children the labels pax or tolen, presented them the label fear. If the results of Study 1A were due to children being unfamiliar with the labels pax or tolen, perhaps they will not match the more familiar label scared to a novel expression.

\section{Method}

The method was identical to that of Study 1A with the following exceptions.

Participants. The ages of participants were: two-year-olds ( $\mathrm{M}=32.9$ mos., $\mathrm{SD}=2.4$ mos.), three-year-olds ( $\mathrm{M}=42.3$ mos., $\mathrm{SD}=3.0$ mos. $)$, and four-year-olds $(\mathrm{M}=53.5$ mos., $\mathrm{SD}=$ 2.6 mos.). In addition, an adult comparison group $(\mathrm{N}=29)$ evaluated materials for this study.

Procedure. Children were primed using the label scared, and instead of being asked if anyone felt pax children were asked "Do you see anyone who feels scared?" In addition, after freely labeling each expression, children labeled the emotion of a story protagonist in a story intended to convey fear. 
Scoring. Responses scored as correct included, for anger: grumpy; for fear: scared.

Table 3. Percentage of children, by age, in each study matching the known label with the novel expression.

\begin{tabular}{|c|c|c|c|}
\hline & \multicolumn{3}{|c|}{ Matching Novel Expressions to Known Labels } \\
\hline & Study $2 \mathrm{~A}$ & Study 2B & Mean \\
\hline \multicolumn{4}{|c|}{ Choice-From-Array Task } \\
\hline 2-year-olds & 68 & - & \\
\hline 3 -year-olds & 75 & -- & \\
\hline 4-year-olds & 88 & -- & \\
\hline 5- and 6-year-olds & -- & 44 & \\
\hline 7- and 8-year-olds & -- & 94 & \\
\hline 9- and 10-year-olds & -- & 81 & \\
\hline Mean & 77 & 73 & 75 \\
\hline \multicolumn{4}{|c|}{ Free Labeling Task } \\
\hline 2-year-olds & 38 & -- & \\
\hline 3 -year-olds & 63 & -- & \\
\hline 4-year-olds & 88 & -- & \\
\hline 5- and 6-year-olds & - & 38 & \\
\hline 7-and 8-year-olds & -- & 87 & \\
\hline 9 - and 10 -year-olds & -- & 87 & \\
\hline Mean & 63 & 71 & 67 \\
\hline
\end{tabular}

\section{Results}

As shown in Table 3, the mean recognition score for preschoolers' matching of the label scared and the novel expression was $77 \%^{2}$. This percentage is significantly greater than the $33 \%$ that would be expected by chance guessing, $t(23)=6.56, p<.001$. Each child had two opportunities to respond that no one in the array felt scared. In only three of these 48 trials did children respond in such a way; in all other trials an expression was selected for the scared label.

For the free labeling task, $63 \%$ of children labeled the novelexpression as scared.

For the choice-from-array task, a 3 (age group) x 3 (emotion label) mixed-design repeated measures ANOVA found that children were more likely to match the expected label with the expressions of happiness than they were to match the label fear with the novel

\footnotetext{
${ }^{2}$ After listening to a story depicting a stereotypical fearful situation, the majority of children (50\%) labeled the story protagonists' emotion as fearful, indicating that children were familiar with the emotion. See Supplemental Information for procedural information and data.
} 
expression, $F(2,42)=4.91, p=.01, \eta_{\mathrm{p}}{ }^{2}=.19(p<.003)$. However, there were no differences between children's matching of fear with the novel expression and their matching of sad with the $\operatorname{sad}$ expression $(p=.17)($ Table 4$)$.

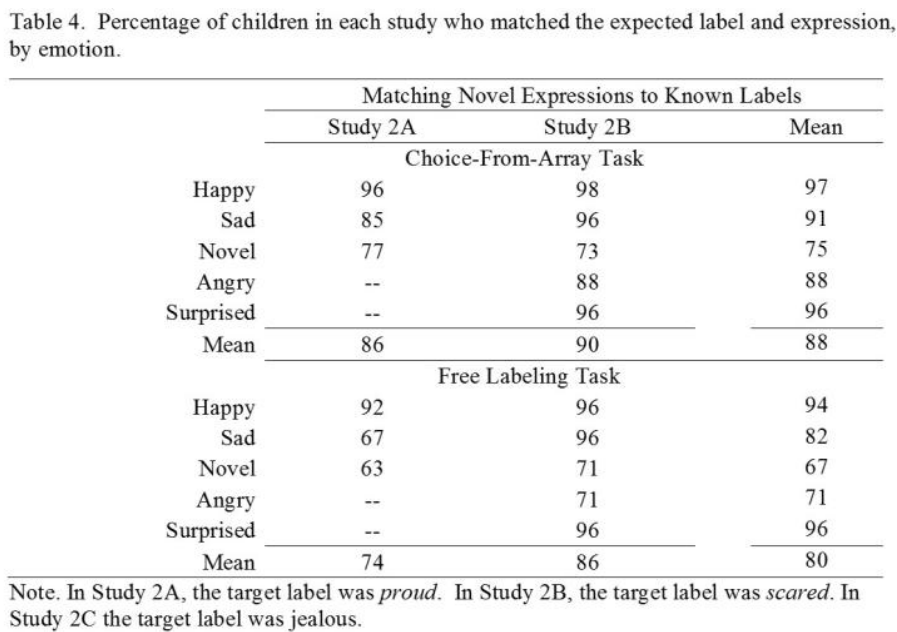

For the free labeling task, $63 \%$ of children labeled the novel expression as scared. Aa 3 (age group) $\mathrm{x}$ (expression) mixed-design repeated measures ANOVA found that children were more likely to match the expected label to the happy expression than to either the sad or novel expressions $F(2,42)=3.23, p=.05, \eta_{\mathrm{p}}^{2}=.13($ all $p$ 's $<.02)$.

\section{Discussion}

The percentage of children who matched the novel expression with the label scared in the choice-from-array task was high and similar to the percentage of children who matched other emotions with the predicted label. Children were as likely to 'recognize' the novel expression as scared as they were to 'recognize' the sad expression as sad. In this study, $77 \%$ of children matched the novel expression with the label scared in the choice-from-array task, a percentage similar to the $62 \%$ of preschoolers matching a fear expression with the label scared in previous research (Izard, 1971). 
In addition, after only a few exposures to the novel expression, $63 \%$ of children (including $88 \%$ of four-year-olds) freely labeled it as scared. Children again appeared to 'recognize' the novel expression as expressing fear, even though the majority of children in the present study demonstrated an understanding of a story depicting a fearful situation (see footnote 2), and children of this age are known to have a well-developed concept of fear (Kayyal \& Widen, 2015).

\section{Study 2B}

It might be argued that five- to ten-year-old children matched the novel expression with novel labels in Study 1B because they believed they were learning a synonym for an emotion concept they were familiar with. Studies 2 A provided evidence against this account for younger children, but older children might still make this assumption. If so, then older children might be less willing to match a novel expression with a familiar label, one that refers to an emotion they have likely experienced. To determine whether older children would match a familiar label to a novel emotional expression, we replicated Study 1B, but rather than asking children to find the person who felt pax, we asked them to find the person who felt jealous. We chose the label jealous because this is an emotion five- to ten-year-olds are likely to be familiar with.

\section{Method}

The method was identical to that of Study 1B with the following exceptions.

Participants. The ages of participants were: five and six-year-olds (M = 69 mos., $\mathrm{SD}=$ 5.3 mos.), seven and eight-year-olds ( $\mathrm{M}=96$ mos., $\mathrm{SD}=7.0$ mos. $)$, and nine and ten-year-olds ( $\mathrm{M}=117$ mos., $\mathrm{SD}=5.5$ mos. $)$.

Procedure. Children were primed with jealous instead of pax, and instead of being asked if anyone felt pax children were asked "Do you see anyone who feels jealous?" 
Scoring. Responses scored as correct included, for jealous: jealous.

\section{Results}

As shown in Table 3, the mean recognition score for children's matching of the label jealous and the novel expression was $73 \%{ }^{3}$. This percentage is significantly greater than the $20 \%$ that would be expected by chance guessing, $t(23)=6.22, p<.001$. Each child had two opportunities to respond that no one in the array felt jealous. For only five of these 48 trials did children respond in such a way; in all other trials, an expression was selected for the jealous label. For the free labeling task, $71 \%$ of children labeled the novel expression as jectous.

For the choice-from-array task, a 3 (age group) x 5 (emotion label) mixed-design repeated measures ANOVA found that children's performance increased with age, $F(2,21)=$ $3.90, p=.04, \eta_{\mathrm{p}}{ }^{2}=.27$, and varied with emotion, $F(4,84)=5.76, p<.001, \eta_{\mathrm{p}}{ }^{2}=.22$ (Table 4). Children were less likely to match the expected label with the novel expression than they were for the happiness, sadness, anger, and surprise (all $p \mathrm{~s}<.02$ ).

\footnotetext{
${ }^{3}$ When children were asked to define jealous, $71 \%$ provided accurate definitions. See Supplemental Information for procedural information and data.

Formatted: Don't add space between paragraphs of the same style (age group) x 5 (expression) mixed-design repeated measures ANOVA showed that children were more likely to label the happy, sad, and surprised expressions than the angry and novel expressions, $F(4,84)=5.60, p<.001, \eta_{\mathrm{p}}{ }^{2}=.21$ (all $p$ 's $\left.<.003\right)$. In addition, seven- and eightyear-olds and nine- and ten-year-olds were more likely to label the novel expression as jealous than the five- and six-year-olds $F(2,21)=4.10, p=.03, \eta_{\mathrm{p}}{ }^{2}=.28($ all $p \mathrm{~s}<.03)$.

\section{Discussion}


The results of this study replicated with older children results from Study 2A with younger children. Although $71 \%$ of children provided an accurate definition of the label jealous, in the choice-from-array task 73\% also 'recognized' the novel expression as jealous. In addition, after only a few exposures to the novel expression, $71 \%$ of children freely labeled it as jealous; five- to ten-year-olds again appeared to 'recognize' the expression presented. These data indicate that older children are willing to match a known label to a made-up emotional expression and may use a process of elimination to do so.

\section{Conclusion}

In the last 40 years, research on children's understanding of facial expressions has found that theyehildren reliably select, for example, the fear face when asked to find someone who is scared. Researchers then concluded that children "recognized"', for example, the fear in the fear face. Five studies here showed that this same method can create illusory recognition. Across the studies here, Return to the puffed checks novel facial expression shown in Figure 1. Across the studies here, that expression was-shown to be "recognized" as an expression of pax, tolen, fear, and jealousy. As shown in Tables 1 and 3, after just a few trials, $74 \%$ of the 120 children tested 
robust and was not contingent upon whether the label presented was an emotion word or not, whether children were familiar with the concepts conveyed by the target label, or whether the label is negative or positive (Nelson \& Russell, 2015b).

Although we included only one novel expression in these studies, we speculate that process of elimination might produce above-chance "recognition" for a greater number of expressions that are unknown to the child. Prior research has used many choice-from-array trials such that children see the same expressions repeatedly; for example, Izard (1971) presented 39 triads, comprised of nine expressions, and children saw each expression 13 times (either as target or distractor). If children used a process of elimination to learn one new label early in athe trial, they can then use that information in later trials to eliminate distractors, and perhaps learn additional labels. Thus, children may learn new expressions across trialsthroughout the trial, divining the expected answer for several unfamiliar expressions by the end of the task, simply using a process of elimination. Indeed, when a study includes many trials, a greater number of participants appear to recognize each expression (Nelson \& Russell, 2013). However, even with just one exposure, children could still produce illusory recognition - if children match a label randomly between two unknown expressions, this would produce $50 \%$ recognition, which would exceed the $33 \%$ typically expected due to chance.

Past research has hinted at the possibility that the choice-from-array task might exaggerate the amount of recognition. Specifically, the percentage of children scored as recognizing a given emotion varies with the number of expressions in the array. When presented arrays of two expressions, preschoolers' performance ranged from 72-85\% (Gagnon, Gosselin, Hudon-ven der Buhs, Larocque \& Milliard, 2010; Russell \& Bullock, 1985). When presented arrays of three or four expressions, preschoolers' performance ranged from $63-71 \%$ (Denham \& 
Couchoud, 1990; Harrigan, 1984; Izard, 1971; Tracy et al., 2005; Walden \& Field, 1982. But see Székely et al., 2011). When presented arrays of ten expressions, preschoolers' performance averaged 44\% (Bullock \& Russell, 1984). That performance decreases as the number of faces in the array increases, suggests that performance in choice-from-array tasks is inflated by guessing, an issue receiving renewed attention in the field of emotion (Cassels \& Birch, 2014; Gendron, 2015).

We do not claim that children are as certain about the association between the novel expression and the label 'pax' or 'fear' as they are about the association between familiarknown expressions like smiles and labels like 'happy'. This is evidenced in children's greater likelihood of labeling familiarknown expressions as expected than labeling the novel expression as 'pax' in manymest of the studies we present. However, our data call into question prior research using choice-from-array tasks: children may have appeared to recognize expressions by relying on a process of elimination.

In past research, the choice-from-array task is sometimes followed by a free labeling task (Harrigan, 1984; Izard, 1971; Markham \& Adams, 1992; Walden \& Field, 1982). However, as shown in Tables 1 and 3, after just two choice-from-array trials, $61 \%$ of the 120 children in these studies went on to spontaneously label the novel expression with the expected label, behavior that increased with age. These data suggest that the choice-from-array task can teach children to associate specific expressions and labels even after only a few trials, and call into question the veracity of free labeling data collected after children completed a choice-from-array task.

Although the results here were robust across various changes in method, an uncountable number of such method changes can be explored. It might be argued that the methods used in the studies presented here differ in some ways from the methods used in prior research using 
choice-from-array tasks. For exampleFor example, in the studies presented here, children were asked to select three or five emotions from an array of three or five expressions, were presented expressions pesed by only two pesers, and were presented the labels in a structured order for each array. Alternatively, in some prior research, children were asked to select only one emotion from an array of three expressions (e.g.: Harrigan, 1984; Izard, 1971; Tracy et al, 2005), were presented expressions posed by several posers (e.g. Bullock \& Russell, 1984; Russell \& Bullock, 1985; Gagnon et al, 2010; Izard, 1971), orand were presented the labels in a random order (Denham \& Couchoud, 1990; Izard, 1971; Harrigan, 1994). Each of these methodological differences may influence the likelihood that children will use a process of elimination strategy, a question that can be answered with future research. However, Izard (1971) found that $62 \%$ of preschoolers matched the expected expression with the expected label, whereas $74 \%$ of preschoolers in the studies presented here matched the novel expression with the expected label. If the use of methods more similar to those used in previous research decreases children's likelihood of matching a novel expression and a target label, their performance may simply drop to be more similar to that of prior research. Unless performance were to decrease to levels lower than expected by chance guessing, these data would still be consistent with the idea that children in prior research could have used a process of elimination strategy to appear to 'recognize' expressions.

As with most research, these studies had limitations. We used static facial expressions, presented in isolation, and in an array - factors that are likely to differ from children's daily experiences with expressions. Thus, the external validity of these studies is unknown. We also primed children with only the three labels used in each study, and presented the expression labels in the same order for each study (i.e. for the first trial, pax was always presented last). It is 
possible that had we expanded the list of priming labels or varied the order of trials, children's

responses may have differed. We also had small sample sizes for each study (precluding the analysis of gender effects due to the small number of male and female participants per cell), which might call into question the validity of our findings. Our results replicated across several studies, however, providing some evidence of robustness of the effect. Finally, it is likely that children's response patterns would vary if two novel expressions were included in the array; future research should examine these variations.

Finally, it might be argued that the results of these studies were due entirely to task demands placed on children, or that children were insufficiently encouraged to respond in the negative to the experimenter's questions, and thus, these results do not truly reflect their reasoning about emotional expressions. Relatedly, it might be argued that the task presented here, in which an expression not intended to convey an emotion was presented as emotional, is a situation children are unlikely to encounter and that, in general, their emotion matching skills are well represented by the choice-from-array task. While we agree that the choice-from-array task can place demands on participants (child or adult) and cause them to respond in ways they would not do spontaneously, we do not agree with the supposition that this concern applies only to 'fake' rather than 'real' expressions. Children are unlikely to be equally familiar with all expressions presented in prior research (children may witness expressions of fear less often than they witness expressions of happiness, for example); arrays that contain unfamiliar expressions would be similar to the arrays presented here. If children are subject to task demands when presented an unfamiliar expression in a choice-from-array task, previous findings could be inflated or even primarily driven by the demands of the task and children's use of the process of elimination, as was the case for children's recognition of 'pax'. 


\begin{abstract}
To the extent that Basic Emotions Theory assumes that even young children innately $\underline{\text { recognize particular, novel, facial movements as displaying a discrete emotion -- recognizing a }}$ fearful expression as displaying fear in their first encounter with the expression, for examplethe parallel assumption must also be made: children must then ignore many non-emotional facial movements during their interactions with others. Non-emotional expressions would be recognized as having no value as emotional signals. The data presented here, however, suggest that children do not view non-emotional expressions as something to be ignored, but rather, as something to be incorporated into their existing emotion knowledge.

Although many variations of Basic Emotions Theory have been suggested in the past 40 years, the core prototypical version of the theory remains the most influential (Russell \& Fernandez Dols, 1997). Even when an author modernizes their theory, or tempers it in the face of new evidence, these changes may not be noted by the field at large (e.g. In the past 3 years, Izard's original theory (1994) has been cited 207 times, whereas his more modern theory, outlined in Quinn et al (2011), was cited just 15 times). The field continues to debate issues related to children's recognition of emotion, partly because, as has been nicely articulated by Quinn et al (2011), although the evidence is weak for infants' recognition of discrete expressions, the possibility still remains, and researchers continue to search for evidence of this phenomenon. Thus, our results are an important addition to a discussion that continues to progress within the field: Extra care must be taken in interpreting data that appear to show that young children recognize emotion from facial expressions, but may be, instead, an artifact of method.
\end{abstract}

Our studies suggest a direction for future research: The process of elimination might be one way in which children acquire emotion labels for facial expressions in non-laboratory 
settings. Children encounter a constant stream of facial movements that may include emotional expressions, but also talking, eating, non-emotional situation-specific behaviors (e.g. squinting in the sun), and any number of additional facial movements. One question is how children learn which particular movements constitute an emotional expression and are associated with a particular emotion. Perhaps, early in their life span, all facial movements are novel for children; certainly, none has a known label. Children might rely on adults' labeling of an expression to determine which movements they should attend to and remember as indicative of emotion. Once a child is familiar with one expression and its label, the child would use a process of elimination to match other expressions with other labels. This hypothesis is consistent with prior research documenting children's use of an elimination strategy to learn categories in a variety of other situations. This process may also ensure that children's expression knowledge is well-tailored to their culture, environment, and individual caregivers. 


\section{References}

Au, T. K., \& Glusman, M. (1990). The principle of mutual exclusivity in word-learning: To honor or not to honor? Child Development, 61, 1474-1490.

Au, T.K., \& Markman, E.M. (1987). Acquiring word meanings via linguistic contrast. Cognitive Development, 58, 1021-1034.

Bullock, M., \& Russell, J. A. (1984). Preschool children's interpretation of facial expressions of emotion. International Journal of Behavioral Development, 7, 193-214.

Camras, L. A., \& Allison, K. (1985). Children's understanding of emotional expressions and verbal labels. Journal of Nonverbal Behavior, 9, 84-94.

Carey, S. \& Bartlett, E. (1978). Acquiring a single new word. Proceedings of the Stanford Child Language Conference, 15, 17-29.

Denham, S. A. (1998). Emotional development in children. New York: Guildford Press.

Denham, S. A., \& Couchard, E. A. (1990). Young preschoolers' understanding of emotions. Child Study Journal, 20, 171-192.

Denham, S. A., McKinley, M., Couchoud, E. A., \& Holt, R. (1990). Emotional and behavioral predictors of peer status in young preschoolers. Child Development, 61, 1145-1152.

Diesendruck, G., Hall, D. G., \& Graham, S. A. (2006). Children's use of syntactic and pragmatic knowledge in the interpretation of novel adjectives. Child Development, 77, 16-30.

Ekman, P. (1980). The Face of Man. New York: Garland Publishing, Inc.

Ekman, P., \& Friesen, W.V. (1978). Manual of the Facial Action Coding System (FACS). Consulting Psychologists Press, Palo Alto, CA.

Frank, M.G., \& Stennett, J. (2001). The forced-choice paradigm and the perception of facial expressions of emotion. Journal of Personality and Social Psychology, 80, 75-85. 
Gagnon, M., Gosselin, P., Hudon-ven der Buhs, I., Larocque, K., \& Milliard, K. (2010).

Children's recognition and discrimination of fear and disgust facial expressions. Journal of Nonverbal Behavior, 34, 27-42.

Gates, G. S. (1923). An experimental study of the growth of social perception. Journal of Educational Psychology, 14, 449-461.

Haidt, J., \& Keltner, D. (1999). Culture and facial expression: Open-ended methods find more expressions and a gradient of recognition. Cognition and Emotion, 13, 225-266.

Harrigan, J. (1984). The effects of task order on children's identification of facial expressions. Motivation and Emotion, 8, 157-169.

Izard, C. E. (1971). The face of emotion. New York: Appleton-Century-Crofts.

Izard, C. E. (1994). Innate and Universal Facial Expressions: Evidence From Developmental and Cross-Cultural Research. Psychological Bulletin, 115, 288-299.

Jennings, K. D. (2004). Development of goal-directed behaviour and related self processes in toddlers. International Journal of Behavioral Development, 28, 319-327.

Kayyal, M. H., \& Russell, J. A. (2013). Americans and Palestinians judge spontaneous facial expressions of emotion. Emotion, 13(5), 891.

Kayyal, M. H., \& Widen, S. C. (2015). What Made Sahar Scared? Imaginary and Realistic Causes in Palestinian and American Children's Concept for Fear. Journal of Cognition and Culture, 15(1-2), 32-44.

Markham, R., \& Adams, K. (1992). The effect of type of task on children's identification of facial expressions. Journal of Nonverbal Behavior, 16, 21-39.

Martens, J. P., Hamlin, J. K., \& Tracy, J. L. (2013, January). Is pride recognition innate?

Developmental origins of understanding the nonverbal pride expression. Poster presented 
at the annual meeting for the Society for Personality and Social Psychology. New

Orleans, LA.

Nelson, N.L., Hudspeth, K., \& Russell, J.A. (2013). A story superiority effect for disgust, fear, embarrassment, and pride. British Journal of Developmental Psychology, 31, 334 - 348.

Nelson, N.L. \& Russell, J.A. (2011a). Putting Motion in Emotion: Do Dynamic Presentations Increase Preschooler's Recognition of Emotion? Cognitive Development, 26, 248-259.

Nelson, N.L. \& Russell, J.A. (2011b). Preschoolers' use of dynamic facial, bodily, and vocal cues to emotion. Journal of Experimental Child Psychology, 110, 52-61.

Nelson, N. L., \& Russell, J. A. (2013). Universality revisited. Emotion Review, 5, 8-15.

Nelson, N.L., \& Russell, J.A. (2015a). Children Distinguish Between Positive Pride and Hubris. Manuscript submitted for publication.

Nelson, N.L., \& Russell, J.A. (2015b). Creating Emotions: Children use a Process of Elimination to Learn aboutAbout Novel Expressions. Manuscript submitted for publication.

Russell, J.A. (1994). Is there universal recognition of emotion from facial expressions? A review of the cross-cultural studies. Psychological Bulletin, 115, 102-141.

Russell, J. A., \& Bullock, M. (1985). Multidimensional scaling of emotional facial expressions: Similarities from preschoolers to adults. Journal of Personality \& Social Psychology, 48, $1290-1298$.

Stipek, D. (1995). The development of pride and shame in toddlers. In J. P. Tangney \& K. W. Fischer (Eds.), Self-conscious emotions (pp. 237-252). New York: Guilford Press. 
Székely, E., Tiemeier, H., Arends, L. R., Jaddoe, V.W.V., Hofman, A., Verhulst, F.C., \& Herba, C. M. (2011). Recognition of facial expressions of emotions by 3-year-olds. Emotion, $11,425-435$.

Tracy, J. L., Robins, R. W., \& Lagattuta, K. H. (2005). Can children recognize the pride expression? Emotion, 5, 251-257.

Walden, T. A., \& Field, T. M. (1982). Discrimination of facial expressions by preschool children. Child Development, 53, 1312-1319.

Waxman, S.R., \& Booth, A.E. (2000). Principles that are invoked in the acquisition of words, but not facts. Cognition, 77, B33-B43.

Waxman, S. R., Lidz, J. L., Braun, I. E., \& Lavin, T. (2009). Twenty four-month-old infants' interpretations of novel verbs and nouns in dynamic scenes. Cognitive Psychology, 59, 67-95.

Wellman, H. M., Harris, P. L., Banerjee, M., \& Sinclair, A. (1995). Early understanding of emotion: Evidence from natural language. Cognition \& Emotion, 9, 117-149.

Widen, S. C. (2013). Children's interpretation of other's facial expressions. Emotion Review, 5, $72-77$.

Widen, S. C. \& Russell, J. A. (2002). Gender and preschoolers' perception of emotion. MerrillPalmer Quarterly, 48, 248-262.

Widen, S. C., \& Russell, J. A. (2003). A closer look at preschoolers' freely produced labels for facial expressions. Developmental Psychology, 39, 114-128.

Widen, S. C., \& Russell, J. A. (2008). Children acquire emotion categories gradually. Cognitive Development, 23, 291-312. 
Wiggers, M., \& Van Lieshout, C. F. (1985). Development of recognition of emotions: children's reliance on situational and facial expressive cues. Developmental Psychology, 21, 338349. 


\section{Highlights}

- Children can use a process of elimination to learn about unfamiliar expressions.

- After only two exposures to an unfamiliar expression, children could label it.

- These data raise concerns about using forced-choice paradigms with children.

- Children may use a process of elimination to learn about expressions in daily life. 
Figure

Click here to download high resolution image

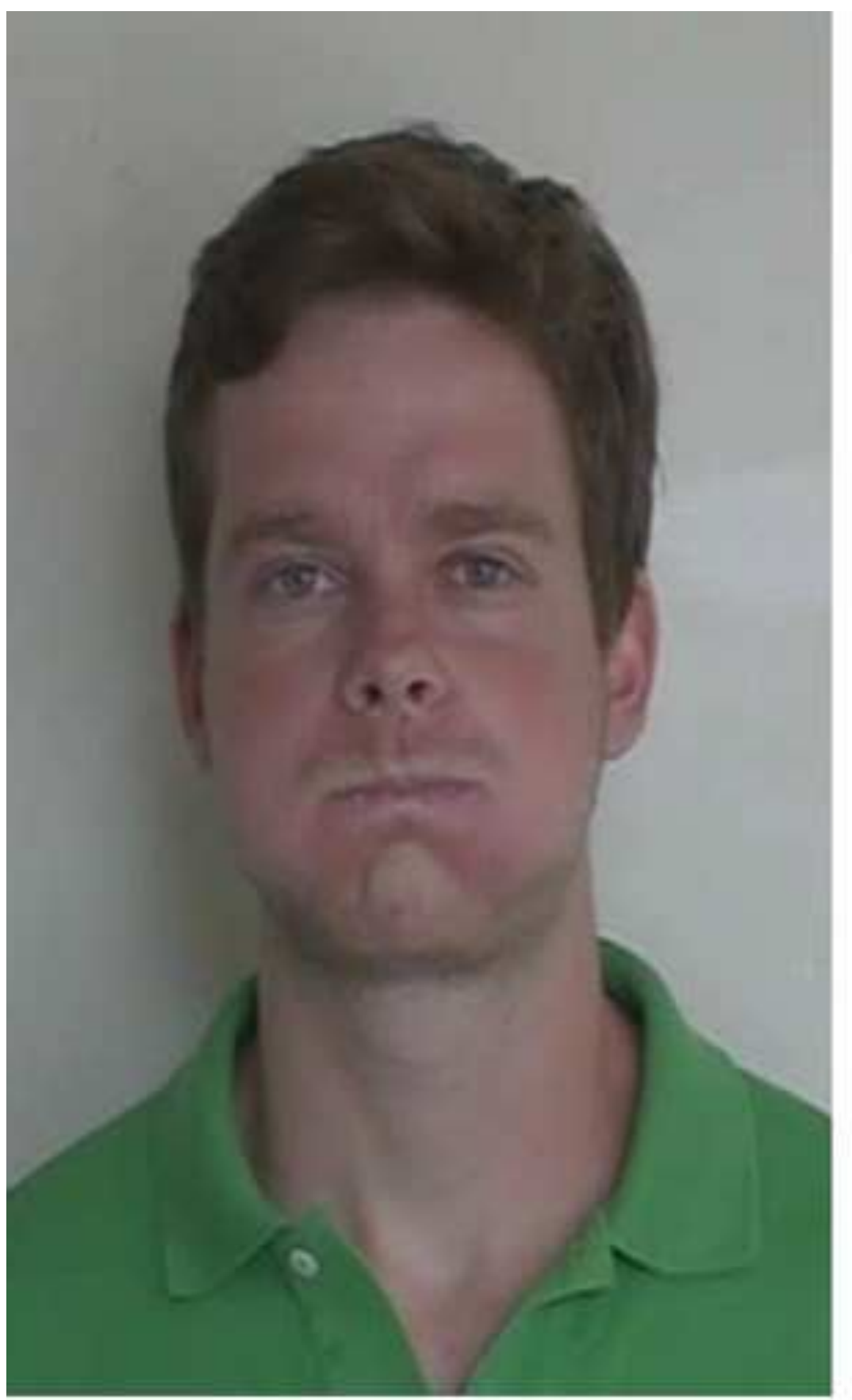

Figure 1. Puffed-cheeks expression. 
Table 1. Percentage of children, by age, in each study matching the novel label with the novel expression.

\begin{tabular}{|c|c|c|c|c|}
\hline & \multicolumn{3}{|c|}{ Matching Novel Expressions to Novel Labels } & \multirow[b]{2}{*}{ Mean } \\
\hline & Study $1 \mathrm{~A}$ & Study IB & Study $1 \mathrm{C}$ & \\
\hline \multicolumn{5}{|c|}{ Choice-From-Array Task } \\
\hline 2-year-olds & 38 & - & -. & 38 \\
\hline 3-year-olds & 81 & - & - & 81 \\
\hline 4-year-olds & 81 &.- & -- & 81 \\
\hline 5 - and 6-year-olds & -. & 63 & 81 & 72 \\
\hline 7 - and 8-year-olds & $\cdots$ & 88 & 75 & 82 \\
\hline 9- and 10-year-olds & - & 63 & 88 & 76 \\
\hline Mean & 67 & 71 & 81 & 73 \\
\hline \multicolumn{5}{|c|}{ Free Labeling Task } \\
\hline 2-year-olds & 13 & -. & - & 13 \\
\hline 3-year-olds & 38 & -. & - & 38 \\
\hline 4-year-olds & 75 & - & - & 75 \\
\hline 5 - and 6-year-olds & - & 50 & 38 & 44 \\
\hline 7 - and 8-year-olds & -. & 88 & 63 & 76 \\
\hline 9- and 10-year-olds & - & 50 & 100 & 75 \\
\hline Mean & 42 & 63 & 67 & 57 \\
\hline
\end{tabular}

Note. The target label was either pax or tolen. 
Table 2. Percentage of children in each study who matched the expected label and expression, by emotion.

\begin{tabular}{|c|c|c|c|c|}
\hline & \multicolumn{3}{|c|}{ Matching Novel Expressions to Novel Labels } & \multirow[b]{2}{*}{ Mean } \\
\hline & Study $1 \mathrm{~A}$ & Study IB & Study $1 \mathrm{C}$ & \\
\hline \multicolumn{5}{|c|}{ Choice-From-Array Task } \\
\hline Happy & 92 & 98 & 92 & 94 \\
\hline Sad & 81 & 90 & 92 & 88 \\
\hline Novel & 67 & 71 & 81 & 73 \\
\hline Angry & -. & 73 & 96 & 85 \\
\hline Surprised & - & 94 & 96 & 95 \\
\hline Mean & 80 & 85 & 91 & 85 \\
\hline \multicolumn{5}{|c|}{ Free Labeling Task } \\
\hline Happy & 71 & 96 & 100 & 89 \\
\hline Sad & 71 & 96 & 92 & 86 \\
\hline Novel & 42 & 63 & 67 & 57 \\
\hline Angry & - & 83 & 67 & 75 \\
\hline Surprised & - & 92 & 88 & 90 \\
\hline Mean & 61 & 86 & 83 & 77 \\
\hline
\end{tabular}

Note. The target label was either pax or tolen. 
Table 3. Percentage of children, by age, in each study matching the known label with the novel expression.

\begin{tabular}{|c|c|c|c|}
\hline & \multicolumn{3}{|c|}{ Matching Novel Expressions to Known Labels } \\
\hline & Study $2 \mathrm{~A}$ & Study $2 B$ & Mean \\
\hline \multicolumn{4}{|c|}{ Choice-From-Array Task } \\
\hline 2-year-olds & 68 & .. & \\
\hline 3-year-olds & 75 & -. & \\
\hline 4-year-olds & 88 & -. & \\
\hline 5- and 6-year-olds & - & 44 & \\
\hline 7- and 8-year-olds & -. & 94 & \\
\hline 9- and 10 -year-olds & $\ldots$ & 81 & \\
\hline Mean & 77 & 73 & 75 \\
\hline \multicolumn{4}{|c|}{ Free Labeling Task } \\
\hline 2-year-olds & 38 & - & \\
\hline 3-year-olds & 63 & - & \\
\hline 4-year-olds & 88 & -. & \\
\hline 5-and 6-year-olds & -. & 38 & \\
\hline 7- and 8-year-olds & - & 87 & \\
\hline 9 - and 10 -year-olds & - & 87 & \\
\hline Mean & 63 & 71 & 67 \\
\hline
\end{tabular}

Note. In Study 2A, the target label was scared. In Study 2B the target label was jealous. 
Table 4. Percentage of children in each study who matched the expected label and expression, by emotion.

\begin{tabular}{|c|c|c|c|}
\hline & \multicolumn{3}{|c|}{ Matching Novel Expressions to Known Labels } \\
\hline & Study $2 \mathrm{~A}$ & Study $2 B$ & Mean \\
\hline \multicolumn{4}{|c|}{ Choice-From-Array Task } \\
\hline Happy & 96 & 98 & 97 \\
\hline Sad & 85 & 96 & 91 \\
\hline Novel & 77 & 73 & 75 \\
\hline Angry & -. & 88 & 88 \\
\hline Surprised & - & 96 & 96 \\
\hline Mean & 86 & 90 & 88 \\
\hline \multicolumn{4}{|c|}{ Free Labeling Task } \\
\hline Happy & 92 & 96 & 94 \\
\hline Sad & 67 & 96 & 82 \\
\hline Novel & 63 & 71 & 67 \\
\hline Angry & -. & 71 & 71 \\
\hline Surprised & -. & 96 & 96 \\
\hline Mean & 74 & 86 & 80 \\
\hline
\end{tabular}

Note. In Study 2A, the target label was proud. In Study 2B, the target label was scared. In

Study $2 \mathrm{C}$ the target label was jealous. 
Click here to download e-component: R2 - Chromium - Supplemental Information.docx e-component
Click here to d 
e-component
Click here to download e-component: R2 - Table 5 - new numbering to S1.jpg 